\title{
Recerca geològica i mineralògica per les comarques del Baix Camp i del Priorat: des del Coll de Teixeta a Porrera, Cornudella del Montsant i a Siurana de Prades
}

Josep Maria Mata-Perelló

Joaquim Sanz Balagué

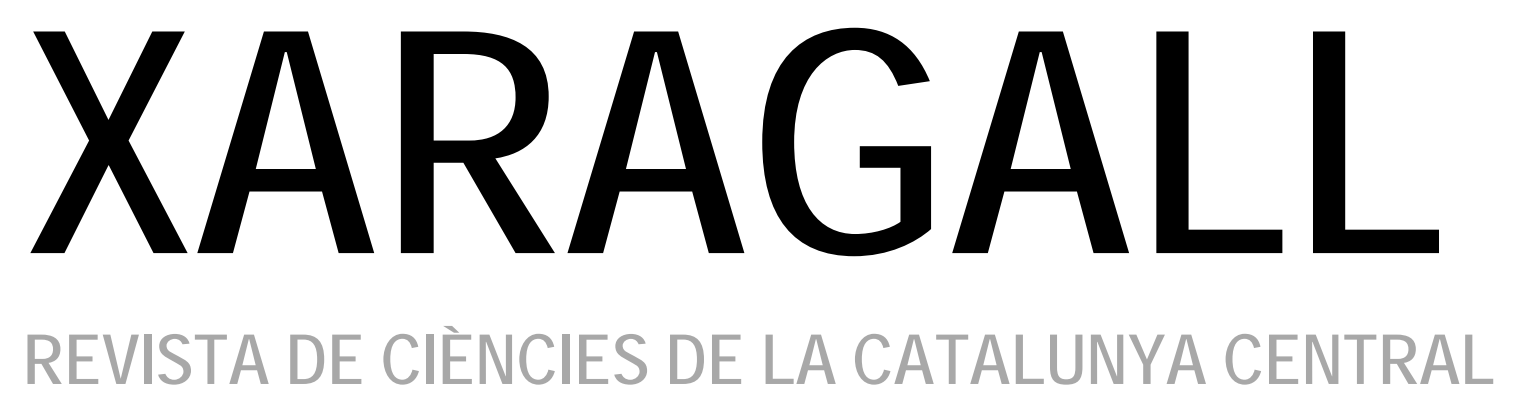

n. 5

MAIG 2015 


\title{
RECERCA GEOLÒGICA I MINERALÒGICA PER LES COMARQUES DEL BAIX CAMP I DEL PRIORAT: DES DEL COLL DE TEIXETA A PORRERA, CORNUDELLA DEL MONTSANT I A SIURANA DE PRADES
}

\author{
Josep Maria Mata-Perelló \\ Museu de geologia Valentí Masachs, Escola Politècnica Superior d'Enginyeria de Manresa \\ (EPSEM), Universitat Politècnica de Catalunya · BarcelonaTech (UPC), 08272 Manresa, Spain
}

\begin{abstract}
Joaquim Sanz Balagué
Departament d'Enginyeria Minera i Recursos Naturals (EMRN), Escola Politècnica Superior d'Enginyeria de Manresa (EPSEM), Universitat Politècnica de Catalunya . BarcelonaTech (UPC), 08272 Manresa, Spain
\end{abstract}

Paraules clau: Sistema Mediterrani, Materials paleozoics, Materials mesozoics, Patrimoni miner

\section{Resum}

Itinerari realitzat el 14 de juny de 2014. En aquesta ocasió, el recorregut del present itinerari discorrerà quasi íntegrament, per una sola de les tres unitats geològiques que constitueixen Catalunya: concretament per la coneguda com a Sistema Mediterrani. Dintre d'aquesta, el recorregut recalarà exclusivament a la seva Serralada Prelitoral Catalana. Tot i així, d'una forma molt breu, també s'entrarà dintre d'una altra unitat geològica catalana, per la Depressió Geològica de l'Ebre, que trobarem al poble de Cornudella del Montsant.

Així, el recorregut s'iniciarà dintre de la primera sotsunitat esmentada, per la qual discorrerà exclusivament entre el Coll de Teixeta i els voltants de Cornudella del Montsant. En aquest tram, trobarem afloraments dels materials paleozoics del Carbonífer. Posteriorment, entre la població abans esmentada i Siurana, tornarem a circular per la Serralada Prelitoral Catalana; tot i que ara, a més a més dels materials paleozoics del Carbonífer, també trobarem afloraments dels materials mesozoics del Triàsic (del Buntsandstein i del Muschelkalk).

Per altra banda, en passar per Cornudella del Montsant, haurem circulat momentàniament, entre els terrenys cenozoics (de l'Eocè) de la depressió Geològica de l'Ebre.

Per altra banda, la quasi totalitat del recorregut del itinerari es desenvoluparà íntegrament per una sola comarca: la del Priorat, tot i que I'haurem començat dintre del Baix Camp (al límit de les dues comarques). 


\section{Objectius fonamentals}

A través d'aquest itinerari geològico-mineralògic, s'intentaran d'aconseguir els següents objectius:

1. Estudi i reconeixement de l'estructura de la Serralada Prelitoral Catalana, pels dos trams on la trobarem: primer entre el Coll de Teixeta i Cornudella del Montsant i després estre aquesta darrera població i la de Siurana de Prades.

2. Estudi i reconeixement dels materials que la constitueixen, de la Serralada Prelitoral Catalana; primer entre el Coll de Teixeta i Cornudella del Montsant i després estre aquesta població i la de Siurana de Prades. En el primer tram veurem i travessarem afloraments dels materials paleozoics del Carbonífer (amb pissarres, esquistos i granodiorites). I en el segon cas, veurem i travessarem afloraments dels materials paleozoics del Carbonífer (com al cas anterior) i dels materials mesozoics del Triàsic (amb nivells de conglomerats, gresos rogencs i calcolutites roges, del Buntsandstein; així com nivells carbonatats de calcaries i dolomies del Muschelkalk Inferior).

3. Estudi i observació de la Depressió Geològica de l’Ebre, per la qual discorrerà el recorregut de l'itinerari en una petita part, per les immediacions de la població de Cornudella del Montsant, exclusivament.

4. Estudi i observació del materials cenozoics del Complex al·luvial del Montsant, que reblen la Depressió Geològica de l'Ebre, pels sectors per on discorrerà l'itinerari, per les immediacions de la població abans esmentada.

5. Observació del contacte entre les dues unitats geològiques que trobarem al llarg del recorregut d'aquest itinerari: això és entre el Sistema Mediterrani (Serralada Prelitoral Catalana) i la Depressió Geològica de l'Ebre. Aquest contacte el trobarem per les immediacions de Cornudella del Montsant.

6. Estudi de diverses mineralitzacions situades fonamentalment a la Serralada Prelitoral Catalana, que anirem trobant al llarg del recorregut de l'itinerari, d'acord amb el següent ordre:

6A) de les mineralitzacions filonianes de $F$, que trobarem a Porrera (Priorat), encaixades entre materials granítics del Carbonífer.

6B) de les mineralitzacions filonianes de $P b-Z n$, encaixades entre els materials de Carbonífer. Les trobarem a Cornudella del Montsant.

6C) de les mineralitzacions estratiformes de $\mathrm{Pb}-\mathrm{Zn}$, situades al Carbonífer. Si s'escau les trobarem prop de Cornudella del Montsant.

6D) de les mineralitzacions evaporítiques de guix, que trobarem al terme de Cornudella del Montsant, situant-se entre afloraments de nivells cenozoics de Depressió Geològica de I'Ebre.

7. Observació de la tipologia de les explotacions mineres relacionades amb les mineralitzacions acabades d'esmentar.

8. Observació dels elements més importants del Patrimoni Miner i del Patrimoni Geològic relacionats amb les explotacions i amb les mineralitzacions anteriors.

9. Observació de les alteracions produïdes sobre el Medi Natural, com a conseqüència de les explotacions mineres acabades d'esmentar; i en tot cas, de la restauració duta a terme. 


\section{Antecedents}

En relació amb el present itinerari, existeix uns antecedents bibliogràfics molt propers. Es tracta d'uns itineraris força semblants al present (MATA-PERELLÓ 1995, 1996a, 1996b, 1998, 2000, 2002, 2008a, 2008b, 2010 i 2011); així com el treball de MATA-PERELLÓ i COLLDEFORNS, 1994. El que ara presentem, constitueix una modificació en relació a aquells. Tret d'aquests, no coneixem altres itineraris d'aquest tipus que discorrin per aquests indrets.

Pel que fa a les mineralitzacions, cal fes esment de l'interessant antecedent de MELGAREJO i DRAPER (1992), referit a les comarques reusenques. Un altre antecedent es troba en MATAPERELLÓ (1991), referit a les mineralitzacions del conjunt dels Països Catalans. També farem esment de CANALS (1985).

Pel que fa als trets de la geologia d'aquestes comarques, ens referirem de nou al treball de MELGAREJO i DRAPER (1992); així com a la publicació de I'IGME (1974). Per d'altra banda, també farem esment de dos treballs referits al conjunt dels Països Catalans. Es tracta dels de: GUIMERÀ et altri (1992) i de RIBA et altri (1979).

Tots aquests treballs, i d'altres, figuraran per ordre alfabètic dintre de l'apartat dedicat a les REFERÈNCIES BIBLIOGRÀFIQUES.

\section{Recorregut de l'itinerari}

El recorregut del present itinerari començarà al bell mig del Coll de la Teixeta, per on es farà la primera aturada. Tot seguit, el recorregut es dirigirà cap a Porrera, seguint la carretera local TP - 7401. En aquesta població hi ha una mina de fluorita, situada al costat del poble. En aquest trajecte, s' ha passat de la comarca del Baix Camp a la del Priorat. En aquest darrer indret, es farà la primera aturada del recorregut de l'itinerari.

Després, el recorregut es dirigia cap al NE, seguint la carretera local TP - 7402 (sortint des de Porrera). En arribar prop de Cornudella del Montsant, a la Venta del Pobill, es trobarà la carretera comarcal $C-242$, per la qual s'anirà cap a la població acabada d'esmentar. En aquest tram es faran diverses aturades, prop de Cornudella del Montsant.

Finalment, el trajecte es dirigirà cap a Siurana de Prades, seguint ara la carretera local que va cap aquest poble. En arribar, finalitzarà l'itinerari, després de fer altres aturades. 


\section{Advertiments previs}

Com en altres recorreguts de RECERCA GEOLÒGICA I MINERALÒGICA ..., si es disposa del temps suficient, poden efectuar-se passant per totes les parades i filloles. En cas contrari, recomanem prescindir de les anomenades PARADES - CONDICIONALS.

També recomanem de cercar la informació més adient, sobre els trams a recórrer mitjançant camins de terra, o de pista. Precisament, en aquest itinerari, hi ha alguns trajectes d'aproximació cap a les mines, que haurem de fer per camins de terra en irregular estat de conservació. Per exemple, aquest és el cas de l'accés a les Mines del Barranc de l'Argentera (del terme de Cornudella de Montsant).

Per altra banda, recomanem tenir una cura extrema de la NATURA, evitant qualsevol forma d'agressió sobre ella, o de fer-n'hi un mal ús del que en ofereix la nostra mare Terra.

\section{Descripció de l'itinerari}

Com en altres itineraris, aquest s'estructurarà en base a una sèrie de PARADES 0 d'ESTACIONS que anirem veient a continuació. En cada una d'aquestes aturades es farà un breu comentari., de tipus geològic o mineralògic, relatiu a l'indret, segons s'escaigui.

Per altra banda, darrera del nom de l'indret situarem (entre parèntesi) el número del full del Mapa Topogràfic, a escala 1:50.000, on es troba situat. En aquest itinerari, utilitzarem exclusivament un sol full: el $\mathbf{4 4 5}$ (o de Cornudella).

A continuació, començarem la descripció de les diferents aturades que formen part del present recorregut.

Així doncs, la relació ordenada de les aturades que composen aquest itinerari, és la següent:

\subsection{Parada 1. COLL DE LA TEIXETA, (termes municipals de Duesaigües i de Porrera, comarques del Baix Camp i del Priorat, respectivament). (Full 445).}

El recorregut del present itinerari el començarem en aquest indret, al límit de les comarques del Priorat i del Baix Camp; concretament dels termes de Porrera i de Duesaigües. Per d'altra banda, aquest indret es troba a la cruïlla de la carretera nacional N - 420 (Tarragona Còrdova, entre Riudecols i Pradell de la Teixeta), amb les carreteres locals TP - 7401 (que es dirigeix cap a Porrera, per on seguirem després) i amb la carretera local T - 313 (que arriba aquí, procedent des de Duesaigües).

Per altra banda, aquest indret es troba totalment situat dintre de la Serralada Prelitoral Catalana (és a dir: dintre del Sistema Mediterrani). Així, si be es veuen per arreu afloraments dels materials paleozoics del Carbonífer. Per d'altra banda, per sobre d'ells apareix uns nivells de gresos, que ja pertanyen al Triàsic Inferior (al Buntsandstein).

Així, en aquest indret es fa ben palesa la discordança entre els materials triàsics del Buntsandstein (constituïts per nivells de gresos i de lutites rogenques, que descansen sobre nivells de conglomerats quarsosos), i els materials del Carbonífer (formats per nivells de pissarres). Per d'altra banda, entre els materials del Buntsandstein es fa ben palesa l'erosió alveolar, amb bons exemples de la mateixa, situant-se entre els nivells dels gresos rogencs. 
Per altra banda, a cantó septentrional del coll, prop d'un antic casalot mig esfondrat, es fa palès un aflorament de roques intrusives, d'unes riolites, entre els materials del carbonífer.

Igualment es fa palesa una falla, entre els materials paleozoics del Carbonífer i el mesozoics del Triàsic inferior (del Buntsandstein). Així, a la mateixa bora de la carretera es pot veure aquesta fractura, així com el seu mirall de falla i les estries. Aquestes darreres es fan molt paleses entre materials del Buntsandstein més durs, els corresponents als nivells de gresos $i$ de conglomerats quarsosos. La falla es fa notablement palesa a la vorera més meridional del coll. També, cal dir que aquest Coll de Teixeta, es troba totalment relacionat amb aquesta falla, de de direcció ENE - WSW, que tanmateix es fa palesa prop de Falset, prop del Coll Roig, a ponent $d^{\prime}$ on ara estem situats. (fotografies 1 i 2 ).

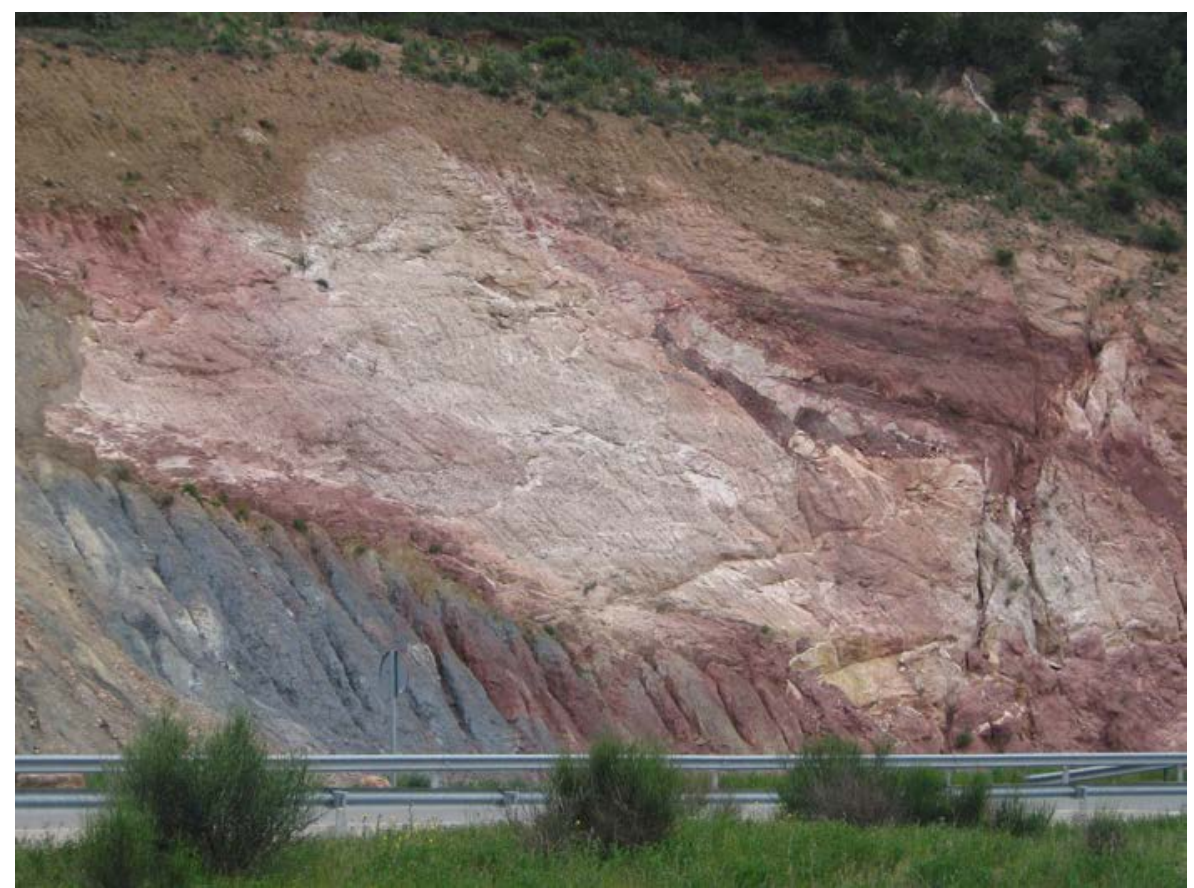

Fotografia 1. Un aspecte de la Falla del Coll de la Teixeta, entre els materials del Buntsandstein Inferior (nivells de conglomerats i gresos quarsosos) i les pissarres del carbonífer 


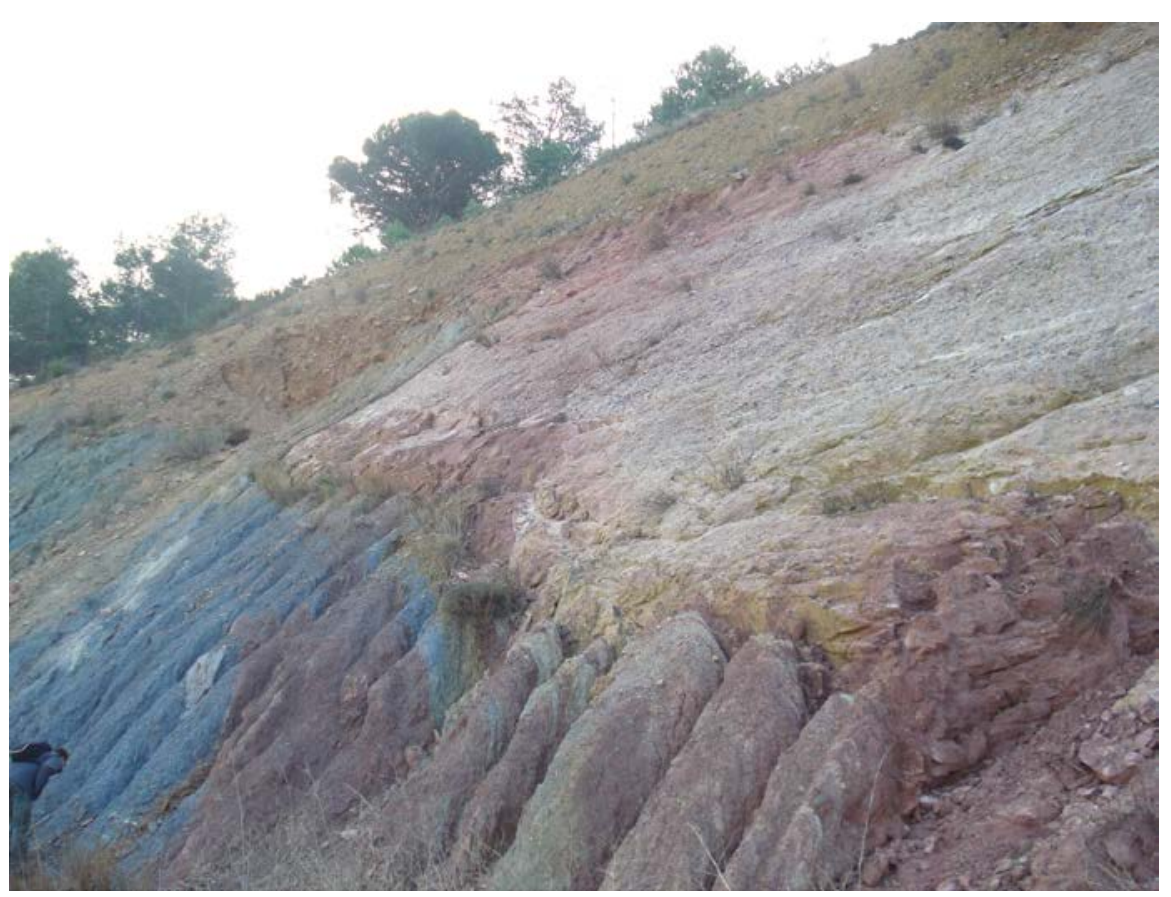

Fotografia 7. Un altre aspecte de la Falla del Coll de la Teixeta.

\subsection{Parada 2. MINES DE FLUORITA, (terme de PORRERA, comarca del Priorat). (Full 445).}

Des de l'indret de la parada anterior pot accedir-se directament a Porrera, tot seguint la carretera que baixa cap al poble, la TP - 7401. Així, després de fer un recorregut proper al 8 $\mathrm{Km}$ s' hi arribarà. Poc abans de fer-ho, caldrà fer una nova aturada dintre d'aquest itinerari.

En tot el recorregut, des del Coll de la Teixeta, s'han anat tallant els materials del Carbonífer (amb lidites i pissarres negres, fonamentalment). Aquests mateixos són també els que apareixen a l'indret de l'aturada.

Pel que fa a la mina, cal dir que es troba situada sobre una mineralització filoniana, la qual es troba encaixada entre pissarres del Carbonífer. Els filons presentes una direcció NE-SW; és a dir: una "direcció catalana".

I, finalment, pel que respecta als minerals presents, cal dir que a més a més de la FLUORITA també s'hi troben es següents minerals: ESFALERITA, GALENA, PIRITA, CALCITA, BARITINA i QUARS. 


\subsection{Parada 3 - CONDICIONAL. MINES DE TURQUESA-VARISCITA DE LA CASA DE LES MORERES, (la Venta del Pobill, terme de Cornudella del Montsant, comarca del Priorat). (Full 445).}

Després de fer l'aturada anterior, cal acabar de travessar el poble de Porrera, per tal de continuar per la carretera local TP - 7402. Per aquesta carretera, després de recórrer uns 8 $\mathrm{Km}$, arribarem a la cruïlla propera a la Venta del Pobill, per on trobarem la carretera comarcal C - 242 (procedent de I'Alforja i que s'encamina cap a Cornudella del Montsant). Des d'aquí, si s'escau ens caldrà agafar el trencall que se'n va cap al Mas de les Moreres. Just, en arribar, es troba el trencall que ascendeix cap al collet, on hi ha les mineralitzacions. Aquí cal aturar-se, a uns $1^{\prime} 5 \mathrm{Km}$ de la cruïlla i a uns $10 \mathrm{Km}$ de parada anterior, aproximadament.

En aquest recorregut, haurem anat travessant afloraments dels materials paleozoics de la Serralada Prelitoral Catalana, en la qual ens continuem trobant. Aquests materials del Carbonífer, són també els que apareixen a l'indret de la parada.

Així, ara ens trobem sobre una afloraments paleozoics del carbonífer, sovint tallats per pòrfirs. Entre aquests materials esquistosos paleozoics, es fan palesos uns filonets, els quals contenen diversos fosfats com TURQUESA i VARISCITA. Aquests fosfats es van intentar explotar, malgrat no ésser gaire abundants, i prop de l'aflorament es troba una antiga galeria, per la qual es volien extreure els materials explotats.

Per altra banda, quasi a tocar d'aquestes mines, hi ha unes antigues explotacions (probablement del calcolític) d'unes mineralitzacions filonianes de coure, fent-se especialment palesa la MALAQUITA.

\subsection{Parada 4. MINES DELS CROSOS, (terme municipal de Cornudella del Montsant, comarca del Priorat). (Full 445).}

Des de la parada anterior, cal retornar a la carretera C-242, per tal de continuar cap a Cornudella del Montsant. Després, en arribar al poble, cal sobrepassar-lo, per tal d'arribar fins a una cruillla situada a menys de $1 \mathrm{Km}$ del poble.

Tot seguit, i des d'aquí, cal continuar per un camí que es dirigeix cap a l'embassament de Cornudella. Poc abans d'arribar-hi, a la dreta de la carretera es troben les antigues mines dels Crosos. Així, en arribar-hi, s'hauran recorregut uns $5 \mathrm{~km}$ des de la parada anterior, aproximadament.

Prop de Cornudella, en aquest recorregut, s'han començat a tallar uns nivells de guixos i d'argiles, els quals pertanyen a l'Eocè, per la qual cosa podem dir que hem circulat momentàniament a la Depressió Geològica de l'Ebre. Després i en un recorregut de 1,5Km., aproximadament, hem passat dels materials terciaris de l'Eocè Inferior, als terrenys paleozoics del Carbonífer, on es troben aquestes mines. És a dir: hem entrat ara a la Serralada Prelitoral Catalana, deixant la Depressió Geològica de l'Ebre.

Des del recorregut cap a les mines, i en especial des de l'embassament, (tot mirant cap a llevant) es fa força palesa la discordança entre els materials mesozoics (del Triàsic), i els paleozoics (del Carbonífer), de la Serra de Prades. Aquesta discordança es posa clarament de manifest a la cinglera de Siurana de Prades, situada a l'altre cantó de l'embassament. Aquest poble es troba sobre les calcàries del Muschelkalk Inferior, les quals descansen sobre els gresos rogencs del Buntsandstein, en contacte discordant amb els materials esquistosos $i$ quarsítics del Carbonífer. 
Pel que fa a les antigues mines (motiu fonamental d'aquesta "parada"), es troben situades sobre unes mineralitzacions filonianes, que encaixen entre els nivells carbonífers, constituïts per esquistos i gresos.

Actualment es impossible penetrar a les mines, i a les seves escombreres es poden trobar mostres dels següents minerals: CALCOPIRITA (indicis), ESFALERITA, GALENA, PIRITA, SIDERITA i QUARS. Igualment es poden trobar minerals d'alteració com: GOETHITA, ATZURITA, CERUSSITA, HIDROCINCITA i MALAQUITA.

De tots els anteriors, els únics minerals que es van intentar aprofitar son el segon i el tercer, sense gaire d'èxit. Aquests minerals són, precisament, els que es fan més palesos a l'escombrera de les mines, conjuntament amb el quars.

\subsection{Parada 5 - CONDICIONAL. MINES DEL BARRANC DE L'ARGENTERA, (terme municipal de Cornudella del Montsant, comarca del Priorat). (Full 445).}

Després de realitzar la parada anterior, cal retrocedir quasi fins l'inici, a la cruïlla amb la carretera comarcal C -242 , per tal de trobar la carretera de Ciurana de Prades, després de recórrer poc menys de $1 \mathrm{Km}$ per l'esmentada carretera comarcal. Després, en trobar el Barranc de I'Argentera, podem fer una nova aturada, després de remuntar el barranc durant $1-2{ }^{\prime} 5$ $\mathrm{Km}$. Així, des de la parada anterior, haurem efectuat un recorregut proper als $5 \mathrm{Km}$, aproximadament.

En aquest recorregut, hem anat trobant, fonamentalment afloraments dels materials del Carbonífer, de la Serralada Prelitoral Catalana. Aquest són també els materials que es troben a l'indret de l'aturada, on ara som.

En aquest indret es troben unes mineralitzacions estratiformes $\mathrm{Pb}-\mathrm{Zn}$ ( $\mathrm{d}^{\prime}$ acord amb MELGAREJO 1992). Entre els minerals presents, cal fer present I'ESFALERITA i la GALENA (molt argentífera).

\subsection{Parada 6. MIRADOR DE SIURANA DE PRADES, (Siurana de Prades, terme municipal de Cornudella del Montsant, comarca del Priorat). (Full 445).}

Després de realitzar l'aturada anterior, cal continuar cap a la població de Siurana de Prades. Després, en arribar al poble, cal sobrepassar-lo, lleugerament per tal de fer la present aturada. Així, haurem recorregut uns $7 \mathrm{Km}$ més.

En aquest recorregut, hem anat trobant primer els materials paleozoics de la Serralada Prelitoral Catalana. Tot seguit, hem trobat els materials triàsics del Buntsandstein (amb gresos rogencs, fonamentalment). Després en arribar prop de Siurana, hem trobat afloraments de les calcaries triàsiques del Muschelkalk Inferior. Aquestes son les que formen el subsòl del poble. (fotografia 3). 


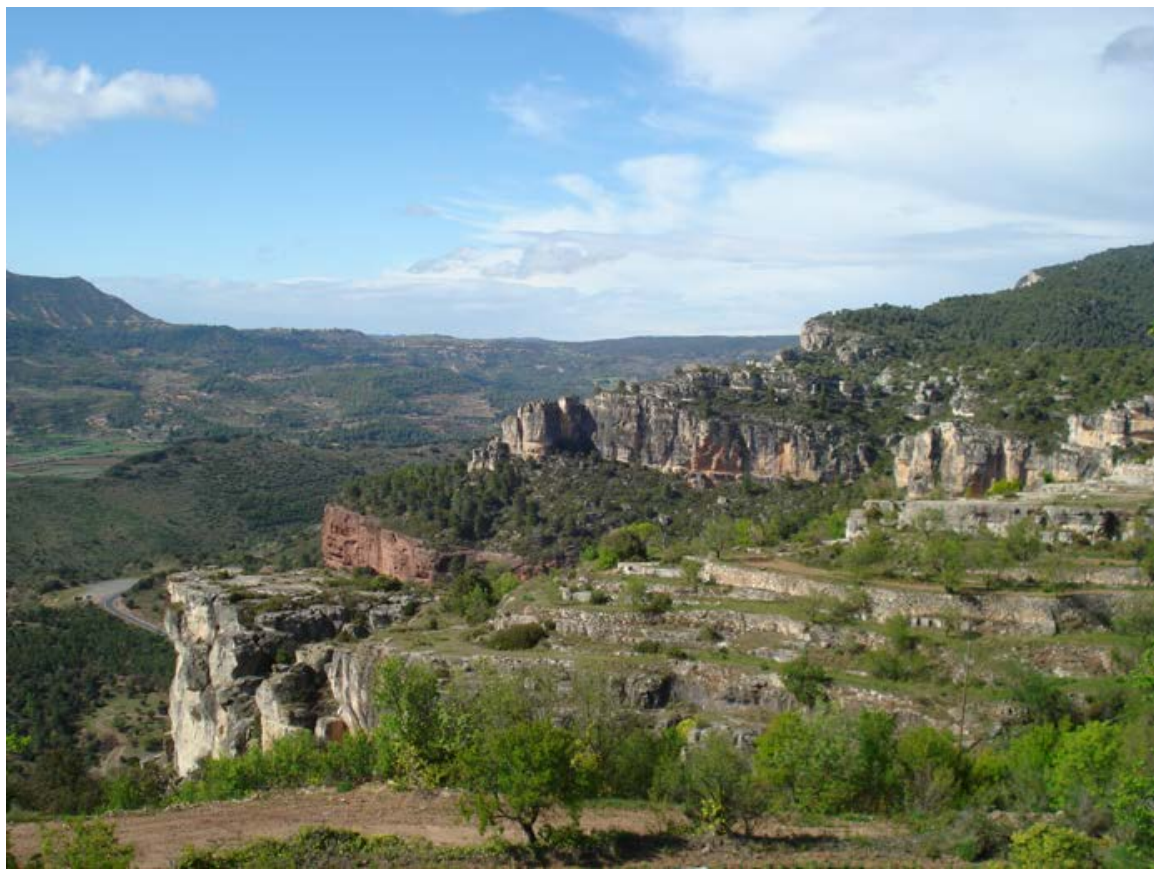

Fotografia 3. Els relleus dels voltants de Siurana. Es fan palesos els materials triàsics per arreu: els rogencs del Buntsandstein (amb gresos) i els més clars del Muschelkalk (amb calcàries)

Sota, amb relleus suaus, apareixen els materials paleozoics. Mentre que lluny, a la dreta de la fotografia, apareixen els terrenys cenozoics del Montsant

\subsection{Parada 7. GUIXERA DE CORNUDELLA., (terme municipal de Cornudella del Montsant, comarca del Priorat). (Full 445).}

Des de l'indret de la parada anterior (a on hem fet una fillola per tal d'anar-hi) cal retornar a la carretera comarcal C-242. En arribar-hi, de seguida trobarem el trencall que condueix cap a les antigues guixeres, on efectuarem la present aturada.

En aquest recorregut hem tornat a trobar els materials terciaris de l'Eocè, per la qual cosa haurem retornat a la Depressió Geològica de l'Ebre. Precisament, aquests materials són els que apareixen a l'indret de l'aturada.

Aquí, hi ha unes antigues guixeres, en una de les quals farem la present aturada. Aquesta guixera, que mostra un bon tall dels materials evaporítics de l'anomenat Complex d'Uldemolins. Aquest tall ens permet recollir bones mostres de GUIX MASSIU, i sovint de GUIX LAMINAR i de GUIX FIBRÓS, formats a partir del primer, per dissolució i precipitació posteriors.

Tanmateix es troben altres minerals, com I'ANHIDRITA, I'HEMIHEDRITA, i fins i tot la CELESTINA (molt minoritària). Per d'altra banda, també es fàcil trobar bones mostres de SILEX, molt freqüent entre els afloraments de l'esmentat Complex d'Ulldemolins. (fotografia 4). 


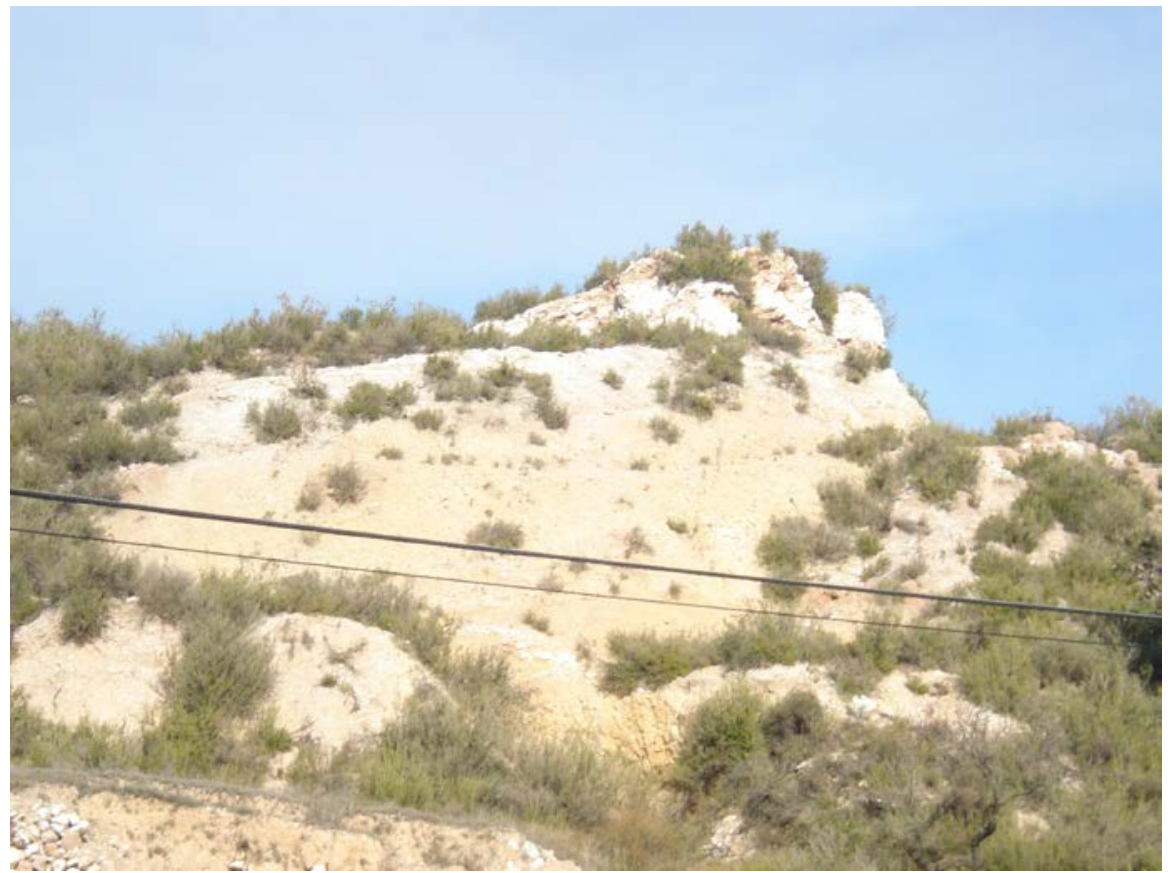

Fotografia 4. Aflorament dels Guixos del Complex d'Ulldemolins. Guixera de Cornudella del Montsant. Depressió Geològica de I’Ebre

En aquest indret finalitza el recorregut de l'itinerari

\section{Bibliografia}

CANALS, C. (1983).- Les mineralitzacions filonianes de I'Argentera i el seu context geològic. Tesi de Llicenciatura, Fac. Geologia. Barcelona.

GUIMERÀ, J. et altri (1992).- Geologia (II), Història Natural dels Països Catalans, Vol. 2, 547 pag. Enciclopèdia catalana, S.A., Barcelona.

IGME (1974).- Mapa Geológico de España a Escala 1:50.000 (2a Sèrie). Full i Memòria no 445 (Cornudella). Inst. Tecnológico y GeoMinero de España. Minist. Indus. Ener. Madrid.

MATA-PERELLÓ, J.M. (1991).- Els Minerals de Catalunya Arxius de la Secció de Ciències, Vol XCIII, 444 pag. Institut d’Estudis Catalans, Barcelona.

MATA-PERELLÓ, J.M. (1995).- Apunts per a un itinerari geològico-mineralògic entre I'Alforja (Baix Camp) i Porrera (Priorat). Inèdit, 12 pàgines. Manresa.

MATA-PERELLÓ, J.M. (1996a).- Itinerari geològic i mineralògic per les comarques del Priorat i del Baix Camp: des de Reus a Cornudella del Montsant, per Prades. Inèdit, 12 pàgines. Manresa.

MATA-PERELLÓ, J.M. (1996b).- Itinerari geològic i mineralògic pel Baix Camp i pel Priorat: des de l’Aleixar a Cornudella, Porrera i al Molar. Inèdit. 6 pàg. Manresa. 
MATA-PERELLÓ, J.M. (1998).- Recerca geològica i mineralògica per les comarques del Baix Camp i del Priorat: des de les Borges del Camp a Prades; i del Coll d'Albarca a Cornudella de Montsant, Xaragall, sèrie $B, \mathrm{n}^{\circ}$ 100, 18 pag. Manresa.

MATA-PERELLÓ, J.M. (2000).- Recorregut de recerca geològica i mineralògica per les comarques del Baix Camp i del priorat: des de les Borges del Camp a Cornudella del Montsant i a la pobla de Cérvoles, Algeps, sèrie $B, n^{\circ} 127,16$ pag. Manresa.

MATA-PERELLÓ, J.M. (2002).- Recerca geològica i mineralògica per les comarques del Baix Camp i del Priorat: des de Reus cap a Riudecanyes, I'Argentera, Duesaigües i a Porrera. Inèdit. 10 pàgines. Manresa.

MATA-PERELLÓ, J.M. (2008a).- Recorregut de recerca geològica i mineralògica per les comarques del Baix Camp i del Priorat: des de Reus a l'Alforja, Cornudella, Ciurana i a Ulldemolins. Inèdit. 16 pag. Manresa.

MATA-PERELLÓ, J.M. (2008b).- Recorregut de recerca geològica i mineralògica per la comarca del Priorat: des de Cornudella del Montsant a Ciurana i a Ulldemolins. Inèdit. 10 pag. Manresa.

MATA-PERELLÓ, J.M. (2010).-Recorregut de recerca geològica i mineralògica per la comarca del Priorat: des de Siurana de Prades a Cornudella del Montsant i a Ulldemolins. Inèdit. 10 pàgines. Manresa.

MATA-PERELLÓ, J.M. (2012).- Recorregut de recerca geològica i mineralògica per la comarca del Priorat: des de Cornudella del Montsant a Siurana de Prades i a Ulldemolins. Inèdit. 12 pàgines. Manresa.

MATA-PERELLÓ, J.M. i COLLDEFORNS, B. (1994). Selecció d'itineraris geològics i mineralògics per les comarques del Baix Camp, Conca de Barberà, Priorat i Ribera d’Ebre. Xaragall, $\mathrm{n}^{\circ}$ 34, 11 pàgines. Manresa.

MELGAREJO I DRAPER J.C. (1992).- Estudio geológico y metalogenético del paleozoico del sur de las Cordilleras Costeras Catalanas. Memórias del Instituto Tecnológico y Geo-Minero de España , tomo 103, 605 páginas. Madrid.

RIBA ARDERIU, O. Et altri. (1976).- Geografía física dels Països Catalans. Edit Ketres. Barcelona. 
XARAGAШ Revista de Ciències de la Catalunya Central 